\title{
Clinical value of 3D printing guide plate in core decompression plus porous bioceramics rod placement for the treatment of early osteonecrosis of the femoral head
}

\author{
Bo $\mathrm{Li}^{1 \dagger}$, Pengfei $\mathrm{Lei}^{2 \dagger}, \mathrm{Hao} \mathrm{Liu}^{3}$, Xiaobin Tian${ }^{1}$, Ting Wen ${ }^{2}$, Ruyin $\mathrm{Hu}^{1 *}$ and Yihe $\mathrm{Hu}^{2 *}$
}

\begin{abstract}
Background: The conventional method of core decompression combined with porous bioceramics rod is usually performed under C-arm fluoroscopy for the treatment of early osteonecrosis of the femoral head (ONFH). This study was to evaluate the clinical value and efficacy of three-dimensional (3D) printing guide plate in the process of core decompression plus porous bioceramics rod for the treatment of early ONFH.

Methods: Forty patients were enrolled, including 20 patients undergoing the surgery with 3D printing guide plate in the experiment group and 20 controls with C-arm fluoroscopy. The following parameters such as surgery time, blood loss, fluoroscopy times, and the accuracy of core decompression for necrosis area, function outcome according to Harris Hip Score (HHS), and any possible complications were recorded and compared between the two groups. All the patients were followed up at 6, 12, and 18 months postoperatively.

Results: The surgery time, fluoroscopy time, and intraoperative blood loss in the experiment group was significantly less $(P<0.05)$ than those in the control group. There was no statistical significance in the accuracy of core decompression and porous bioceramics rod placement between the two groups $(P>0.05)$. All patients were followed up for 18 months. There was a significant difference between the preoperative and final follow-up HSS scores in both groups $(P<0.05)$. In addition, there was also a significant difference between the groups in the last follow-up HSS scores $(P<0.05)$.

Conclusions: Compared with the traditional method, 3D printing guide plate could shorten the surgery time and fluoroscopy times and decrease intraoperative blood loss. It seems to be an effective method in the combined core decompression with porous bioceramics rod placement for early ONFH.
\end{abstract}

Keywords: Femur head necrosis

\footnotetext{
* Correspondence: guizhouhuruyin@163.com; csuhuyihe@163.com

${ }^{\dagger} \mathrm{Bo}$ Li and Pengfei Lei contributed equally to this work.

'Department of Orthopaedics, Guizhou Provincial People's Hospital, Guiyang

550002, Guizhou, People's Republic of China

${ }^{2}$ Department of Orthopaedics, Xiangya Hospital of Central South University,

Changsha, People's Republic of China

Full list of author information is available at the end of the article
}

(c) The Author(s). 2018 Open Access This article is distributed under the terms of the Creative Commons Attribution 4.0 International License (http://creativecommons.org/licenses/by/4.0/), which permits unrestricted use, distribution, and reproduction in any medium, provided you give appropriate credit to the original author(s) and the source, provide a link to the Creative Commons license, and indicate if changes were made. The Creative Commons Public Domain Dedication waiver (http://creativecommons.org/publicdomain/zero/1.0/) applies to the data made available in this article, unless otherwise stated. 


\section{Background}

Osteonecrosis of the femoral head (ONFH) is a catastrophic disease of the femoral head and affects younger patients in their thirties and fifties. ONFH has complex and poorly understood pathogenesis and, if left untreated, may seriously damage the hip joint's function [1-3]. For ONFH within the reversible stage, core decompression of the necrotic area represents an established and commonly used technique. This therapeutical principle was developed by Ficat and Arlet in 1962 during diagnostic "functional exploration of bone" [4]. In the reversible stages, i.e. , Steinberg stage I, II, and III, core decompression is supposed to reduce the intraosseous pressure and bring about reperfusion. Core decompression can be modified by additional interventions such as implantation of bone marrow cells, growth factors, or fibular grafting [5-7]. Porous biocramics beta-tricalcium phosphate is a new type of implantable biomaterial in orthopedic surgery [8, 9]. Core decompression combined with porous bioceramics rod implant is one of most effective methods in treating the early ONFH [10]. Although most surgeons can perform core decompression under a $\mathrm{C}$-arm fluoroscopic imaging system, there still remains a challenge to achieve the precise location of the necrosis area and shorter operation and fluoroscopy time.

Three-dimensional (3D) printing has gradually penetrated into the field of clinical medicine [11], which may probably be used to guide the core decompression operations for the patients with ONFH. Specifically, the 3D printing technology could produce a joint surgical guide plate which can be used to preoperatively estimate the necrosis area and depth of core decompression, and mimic placing the porous bioceramics rod. Besides, based on the individualized 3D printing model, surgeons could have a better understanding of the anatomical structure and the disease, which may contribute to shorten operation time, promote surgery accuracy, and reduce complications [12]. To our knowledge, there are few reports regarding $3 \mathrm{D}$ printing used in the combined core decompression and porous bioceramics rod placement [13]. In this study, we aimed to assess the clinical value and efficacy of $3 \mathrm{D}$ printing model in the combined surgery for the treatment of ONFH.

\section{Methods}

The study was approved by the Ethics Committee of Guizhou Provincial People's Hospital (series number: 2017-009). Written informed consent was obtained from each subject.

\section{Patients and methods}

Patients with early ONFH receiving the core decompression plus porous bioceramics rod placement from October 2015 to June 2016 were enrolled for this study. ONFH was diagnosed according to radiological examination and clinical evidence. Patients were preoperatively evaluated using Steinberg staging. The inclusion criteria were as follows: Steinberg stage I, II, or IIIA and consistent hip pain for at least 6 months without obvious improvement after non-operational treatment. The exclusion criteria were as follows: bone lesions but not conform to femoral head necrosis and Steinberg stage IIIB, IIIC, IV, or V. The written informed consents of all patients were obtained.

The patients were assigned into experimental group and control group according to the decision of therapeutic regimen made by the chief surgeons. Patients in the experimental group received core decompression with porous bioceramics rod placement assisted by $3 \mathrm{D}$ printing guide plate, while patients in the control group had the same surgery under the traditional X-rayassisted procedure.

\section{Surgical procedures}

All patients underwent preoperative imaging examination, such as hip joint-anterior/lateral radiographs, MRI, and CT for protopathic certification (Fig. 1). In the experimental group, preoperative thin-slice CT scans of the hip joint were obtained using the Siemens 64 row spiral CT (Siemens, Munich, Germany). The scanning parameters were as follows: scanning voltage, $130 \mathrm{kV}$; scanning thickness, 0 . $625 \mathrm{~mm}$; and the matrix, $512 \times 512$. Digital imaging and communications in medicine format $\mathrm{CT}$ data were imported into Simpleware 7.2 (Simpleware Ltd., Exeter, UK) to reconstruct the 3D hip model of stereolithography format. The experimental group received hip joint $\mathrm{CT} 3 \mathrm{D}$ reconstruction with a layer of $0.625 \mathrm{~mm}$. The digital design was created using Geomagic (3D Systems, Valencia, CA, USA). The 3D printer was used, and the printing material was polyamide PA2200 (Fig. 2). The bio-model and its corresponding template were placed together, and a standard electric power drill was used to locate the decompression trajectory into the bio-model at the predefined site. 3D printing guide plate was sterilized before the operation.

The operation in both groups was performed in a minimally invasive lateral approach $(3-4 \mathrm{~cm})$ by the same surgeon. The patient was in the supine decubitus position with the affected hip draped freely. The fascia lata and the vastus lateralis muscle were split down to the lateral side of the proximal part of the femur. After full exposure, the 3D printing guide plate was tightly attached to the proximal part of the femur, and one Kirschner wire was inserted into the pinhole on the guide plate to obtain a core decompression position. Then, a guide needle was inserted from the lateral femoral cortex into the necrosis area to guide the drilling hole with a special core reamer $(8-10 \mathrm{~mm}$ in diameter), and finally, a bony channel up to about $5 \mathrm{~mm}$ depth underneath the articular cartilage surface was established. The needle and reamer were withdrawn. The core 


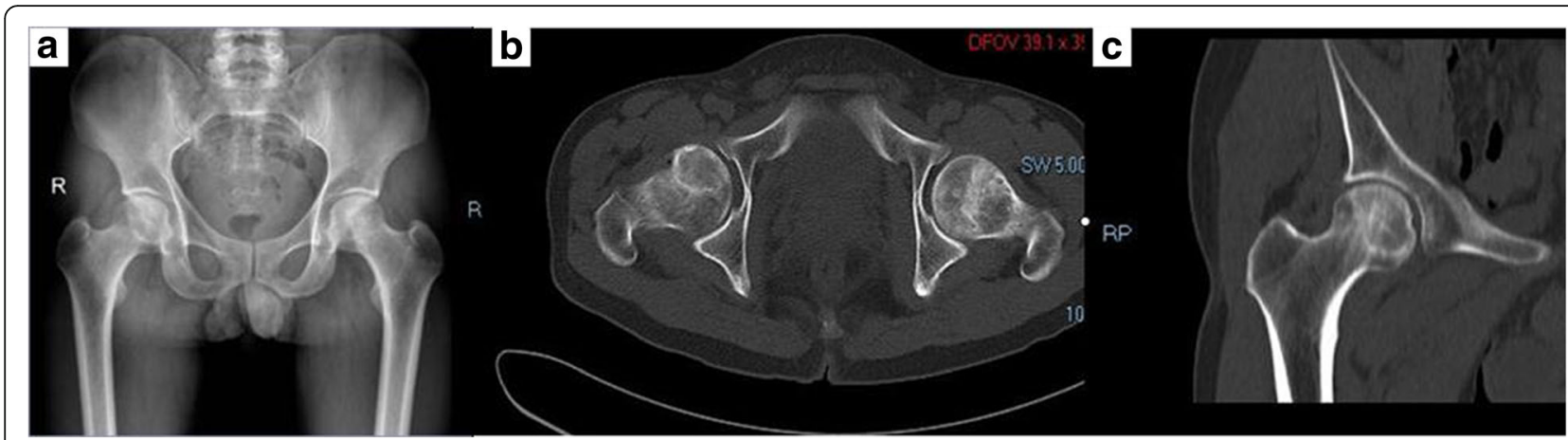

Fig. 1 a-c Pre-operative $X$-ray and CT images of hip joint

decompression was done: the necrotic bone and granulation tissue were scraped thoroughly with a curette. After core decompression, a porous bioceramics rod $(10 \mathrm{~mm}$ in diameter and $90 \mathrm{~mm}$ in length) purchased from Shanghai Bio-lu Biomaterials Co., Ltd., China, was inserted according to the depth of the channel. C-arm fluoroscopy was used to confirm the angle, position, and depth of core decompression. The control group received traditional X-ray-assisted core decompression and porous bioceramics rod placement.

\section{Clinical evaluation and follow-up}

Radiologic evaluation included standard anteroposterior and lateral X-ray and hip joint. CT examinations were performed in each patient preoperatively and 6 months,
12 months, and 18 months postoperatively. The following indexes were recorded, including the intraoperative blood loss, surgical time, fluoroscopy times, the accuracy of core decompression for necrosis area, and any possible complications in both groups. The amount of intraoperative blood loss was roughly calculated by the amount of blood in suction bottle and the weight gain of the gauze. Accuracy of core decompression was defined as the successful positioning of Kirschner wire in the necrosis area.

Outcomes were measured and recorded by Harris Hip Score (HHS) which contains four items: pain, function, activity, and motion of the hip. The HHS was categorized as excellent (90-100 points), good (80-89 points), fair (70-79 points), or poor (<69 points).

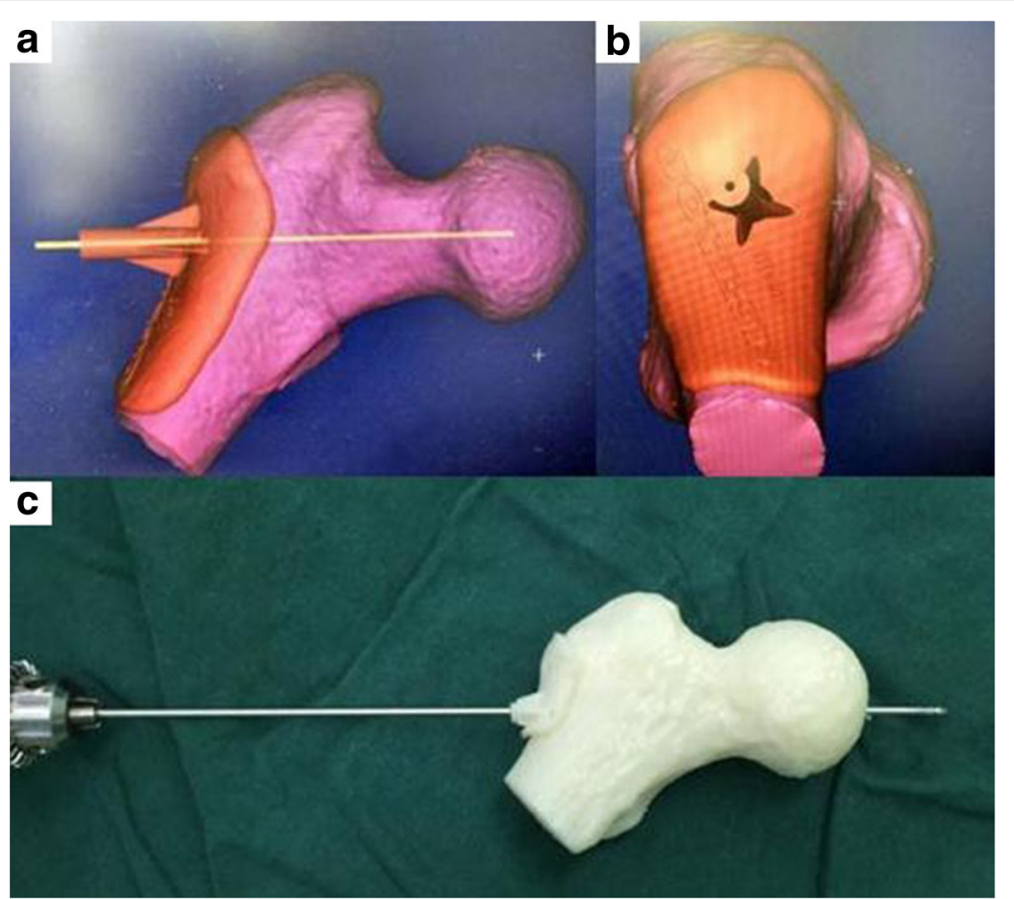

Fig. 2 a The pre-operative 3D CT reconstruction images. b A virtual guide pin path was established on the proximal femur model using MedCAD making the path reach to the target region. c The guide pin path was established with the assistance of the corresponding guide pin guide plate, which was performed at the opposite side by the same method 
Statistical analysis Statistical analysis was performed with SPSS 19.0 Statistical software. Parametric data are presented as means \pm standard deviation (SD) and compared with the independent $t$ test. Non-parametric data are expressed as percentage and compared with the $\chi^{2}$ test. A $P$ value of less than 0.05 is considered as significant.

A post hoc power analysis was performed using a G*Power software [14] (version 3.1; Düsseldorf University, Düsseldorf, Germany) for each sample size of the cohorts and the means (and standard deviations) of the outcome measure surgical time of each group, resulting in a power value of 0.95 .

\section{Results}

\section{Baseline data}

A total of 40 patients were enrolled at our service between October 2015 and June 2016 regarding their eligibility for the present study. In the experimental group (11 males, 9 females; average age $42.3 \pm 5.2$, range of $35-50$ years), there were six hips with stage I ONFH, eight hips with stage II, and six hips with stage IIIA. In the control group (14 males, 6 females; average age $39.7 \pm 6.4$, range of 3148 years), there were seven hips with stage I ONFH, six stage II, and seven stage IIIA. The baseline characteristics of the participants in the groups were compared, and the results are described in Table 1. There was no statistically significant difference regarding age, sex, BMI, etiologic factors, Steinberg stage, and preoperative Harris Hip Score between the two groups (all $P>0.05$ ).

\section{Surgical profiles}

The surgical profiles were shown in Table 2. The surgery time $(29.9 \pm 2.1 \mathrm{~min})$ in the experiment group was significantly less $(P<0.05)$ than that of the control group
$(40.5 \pm 2.2 \mathrm{~min})$. There was less intraoperative blood loss in the experiment group $(18.0 \pm 11.1 \mathrm{~mL})$ than that of the control group $(39.9 \pm 13.0 \mathrm{~mL})$ with statistical significance $(P<0.05)$. The fluoroscopy times for core decompression and porous bioceramics rod placement were 0 . $9 \pm 0.4$ in the experimental group and $4.1 \pm 0.7$ in the control group $(P<0.05)$, respectively.

\section{Surgical results and complications}

The accuracy of core decompression and porous bioceramics rod placement was good in $20(100 \%)$ in the experimental group and $18(90 \%)$ in the control group, with no statistical significance $(P>0.05)$. The post-operative anteroposterior and lateral X-ray film and hip joint $\mathrm{CT}$ showed that core decompression and porous bioceramics rod placement was satisfactory (Fig. 3). No obvious complications were observed in either group.

All patients were followed up for 18 months. The Harris scores in both groups postoperatively at different followup periods were statistically significantly improved in comparison to that of the preoperative values. In addition, there were statistically significant differences between the two groups regarding the postoperative Harris scores at 6 , 12 , and 18 months of follow-up $(P<0.05)$ (Table 3$)$.

\section{Discussion}

With the rapid progression of digital technology, the clinical applications of 3D measurement and operative simulation have gradually increased. The $3 \mathrm{D}$ printing technique is a modality of rapid prototyping (RP) technique based on 3D models and uses computer software and CNC forming system to produce a physical product using special materials, such as metal powder, ceramic powder, and cellular tissue. In orthopedic surgery, this technique is based on the

Table 1 Patient characteristics ( $n=40$, means \pm SD)

\begin{tabular}{|c|c|c|c|}
\hline & Experiment group $(n=20)$ & Control group $(n=20)$ & $P$ values \\
\hline Age, years & $42.30 \pm 9.20$ & $39.70 \pm 8.40$ & 0.357 \\
\hline Sex & & & 0.327 \\
\hline Male & 11 & 14 & \\
\hline Female & 9 & 6 & \\
\hline BMl & $24.95 \pm 2.59$ & $24.47 \pm 2.05$ & 0.152 \\
\hline Etiologic factors, number of hips (\%) & & & 0.414 \\
\hline Alcohol & 10 & 7 & \\
\hline Steroids & 7 & 11 & \\
\hline Idiopathic & 3 & 2 & \\
\hline ARCO stage & & & 0.803 \\
\hline । & 6 & 7 & \\
\hline$\|$ & 8 & 6 & \\
\hline$\| \mathrm{A}$ & 6 & 7 & \\
\hline Preoperative Harris Hip Score & $72.70 \pm 3.81$ & $70.40 \pm 3.36$ & 0.051 \\
\hline
\end{tabular}


Table 2 Surgical profiles in two groups

\begin{tabular}{llll}
\hline & $\begin{array}{l}\text { Experiment group } \\
(n=20)\end{array}$ & $\begin{array}{l}\text { Control group } \\
(n=20)\end{array}$ & $P$ \\
\hline Surgery time, min & $29.93 \pm 2.13$ & $40.51 \pm 2.24$ & 0.001 \\
Intraoperative blood loss, $\mathrm{ml}$ & $18.04 \pm 11.14$ & $39.91 \pm 13.03$ & 0.001 \\
Fluoroscopy times & $0.92 \pm 0.41$ & $4.14 \pm 0.73$ & 0.001 \\
\hline
\end{tabular}

CT scan image to rebuild the target bones including other anatomical structures. RP has demonstrated significant potential as an effective visualization tool alongside the conventional imaging methods for preoperative planning and intraoperative surgical guidance [15]. RP technique is mainly applied in dentistry and maxillofacial surgery [16]. The 3D printing individual guide plates have been reported to be successfully used in spinal surgery, joint surgery, and tumor surgery [17-19]. The 3D printed "polyamide PA 2200 " plate has excellent properties of heat resistance, abrasion resistance, mechanical strength, and mechanical property. It can maintain a certain strength and is not easily deformed. During the installation of the guide plate and the operation process, the accuracy will not be affected due to the deformation of the guide plate. Several small holes on the guide plate were designed for the insertion of K-wire, so as to anchor the plate on the femur.
This study showed that $3 \mathrm{D}$ printing guide plates played a positive role in the combined core decompression with porous bioceramics rod for early ONFH. It shortened operation time and fluoroscopy time and decreased blood loss.

As for the accuracy of core decompression and porous bioceramics rod placement, there was no statistical significance between the two groups. This was possibly due to that most of the patients in the present study were without anatomical abnormality, and thus, the surgeon could achieve satisfactory result with his experience and the help of intraoperative fluoroscopy.

There are several advantages in 3D printing individual guide plate. Firstly, the anatomical morphology was shown in the surgical plan prior to surgery. Thus, the surgeon can have a better master of the location, angle, orientation, and the depth of the core compression. Secondly, it is simple to apply and does not request much expertise of the surgeon; the preoperatively prepared individual guide plate can be used intraoperatively to assist with surgical navigation and precise location of the instrumentation. Thirdly, core decompression could be accurately performed which avoids damaging the articular cartilage. Fourthly, in contrast to the traditional X-ray-assisted method, this technique eliminates the need for complex

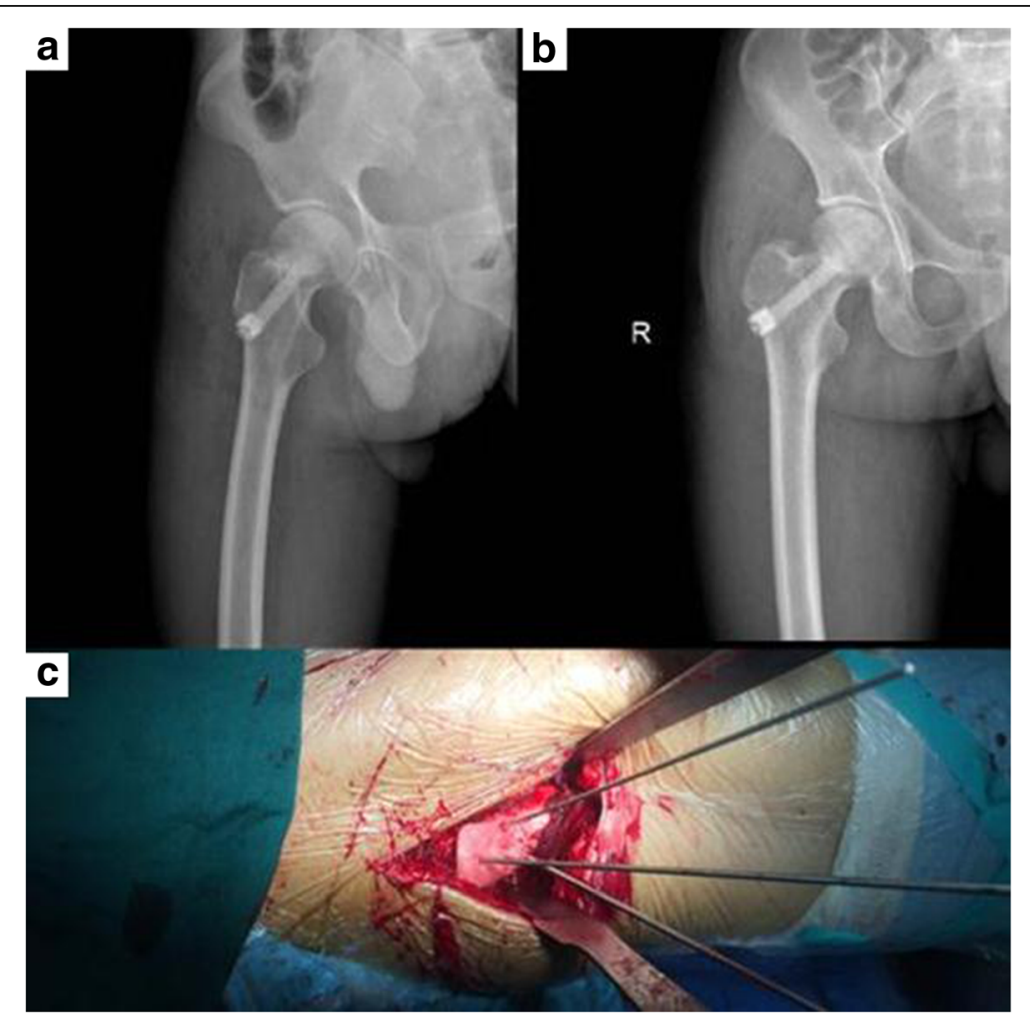

Fig. 3 a The post-operative lateral X-ray films. $\mathbf{b}$ The post-operative anterior-posterior $X$-ray films, which showed the good position of core decompression with porous bioceramics rod. $\mathbf{c}$ The guide pin path was established under the assistance of individualized 3D guide plate during the operation 
Table 3 Harris scores in two groups

\begin{tabular}{lllll}
\hline & Preoperatively & 6 months postoperatively & 12 months postoperatively & 18 months postoperatively \\
\hline Experiment group $(n=20)$ & $72.70 \pm 3.81$ & $88.55 \pm 1.47^{\mathrm{a}, \mathrm{b}}$ & $91.80 \pm 1.51^{\mathrm{a}, \mathrm{b}}$ & $94.20 \pm 0.95^{\mathrm{a}, \mathrm{b}}$ \\
Control group $(n=20)$ & $70.40 \pm 3.36$ & $83.75 \pm 2.23^{\mathrm{a}}$ & $89.65 \pm 1.46^{\mathrm{a}}$ & $91.85 \pm 0.99^{\mathrm{a}}$ \\
$P$ values & 0.051 & $<0.05$ & $<0.05$ & $<0.05$ \\
\hline
\end{tabular}

av preoperative values, $P<0.05$

bs control group, $P<0.05$

equipment and time-consuming procedures in the operating room; thus, it decreases the surgical duration.

The technique also has potential sources of error [20, 21]. If without sufficient thin cuts of CT scans, it may lead to an inaccurate 3D representation of the bony surface and a poorly fitting drill template. The RP model could deviate from the computer 3D model, but existing RP technology can control deviation to $0.1 \mathrm{~mm}$. This technique requires more clean preparation of the bone surface than in conventional surgeries, including thorough removal of the attached muscle and soft tissue without any potential damage to the bony surface structure. In this circumstance, soft-tissue release takes certain time. However, the repeated positioning by $\mathrm{C}$-arm fluoroscopy will cost much more surgical time. Thus, the $3 \mathrm{D}$ printing guide plate technique reduced the surgery time and fluoroscopy time relative to the C-arm fluoroscopy technique.

\section{Conclusions}

Compared with the traditional method, 3D printing guide plate could shorten the operation time and fluoroscopy time and decrease intraoperative blood loss. It is suggested that $3 \mathrm{D}$ printing guide plate seems effective in the combined core decompression with porous bioceramics rod placement for early ONFH.

\section{Abbreviations}

3D: Three-dimensional; ONFH: Osteonecrosis of the femoral head; RP: Rapid prototyping

\section{Funding}

This project was supported by the Science and Technology Cooperation Project of Guizhou Province of China (LH[2014]7006), Science and Technology Project of Guizhou Province of China (SY[2015]3044), Science and Technology Cooperation Project of Guizhou Provincial Health and Family Planning Commission (gzwjkj2015-1-025), and 2017 Youth Fund of Xiangya Hospital of Central South University (2017Q07).

\section{Availability of data and materials}

The dataset(s) supporting the conclusions of this article is (are) included within the article and its supplementary information files.

\section{Authors' contributions}

$\mathrm{PL}, \mathrm{BL}, \mathrm{RH}$, and $\mathrm{YH}$ designed the study. PL wrote the manuscript and conducted the literature searching. BL interoperated the data. $\mathrm{HL}$ analyzed the data. XT and TW collected the data. All authors read and approved the final manuscript.

\section{Ethics approval and consent to participate}

The study was approved by the Ethics Committee of People's Hospital of Guizhou Province and Xiangya Hospital of Central South University. Written informed consent was obtained from each subject.

\section{Consent for publication}

All patients included in the study provided their informed consent at enrolment and the use of patients' data for research.

\section{Competing interests}

The authors declare that they have no competing interests.

\section{Publisher's Note}

Springer Nature remains neutral with regard to jurisdictional claims in published maps and institutional affiliations.

\section{Author details}

'Department of Orthopaedics, Guizhou Provincial People's Hospital, Guiyang 550002, Guizhou, People's Republic of China. 'Department of Orthopaedics, Xiangya Hospital of Central South University, Changsha, People's Republic of China. ${ }^{3}$ Department of Surgery, University of Pittsburgh, Pittsburgh, PA 15213, USA

Received: 5 December 2017 Accepted: 17 April 2018

Published online: 30 May 2018

References

1. Rajpura A, Wright AC, Board TN. Medical management of osteonecrosis of the hip: a review. Hip Int. 2011;21:385-92.

2. Malizos KN, Karantanas AH, Varitimidis SE, Dailiana ZH, Bargiotas K, Maris T. Osteonecrosis of the femoral head: etiology, imaging and treatment. Eur J Radiol. 2007;63:16-28.

3. Jones LC, Hungerford DS. Osteonecrosis: etiology, diagnosis, and treatment. Curr Opin Rheumatol. 2004;16:443-9.

4. Ficat RP. Idiopathic bone necrosis of the femoral head. Early diagnosis and treatment. J Bone Joint Surg Br. 1985;67:3-9.

5. Mont MA, Marulanda GA, Seyler TM, Plate JF, Delanois RE. Core decompression and nonvascularized bone grafting for the treatment of early stage osteonecrosis of the femoral head. Instr Course Lect. 2007;56:213-20.

6. Mont MA, Jones LC, Seyler TM, Marulanda GA, Saleh KJ, Delanois RE. New treatment approaches for osteonecrosis of the femoral head: an overview. Instr Course Lect. 2007:56:197-212.

7. Hungerford MW, Mont MA. Potential uses of cytokines and growth factors in treatment of osteonecrosis. Orthopade. 2000;29:442-8.

8. Descamps M, Duhoo T, Monchau F, Lu J, Hardouin P, Hornez JC, Leriche A. Manufacture of macroporous $\beta$-tricalcium phosphate bioceramics. J Eur Ceram Soc. 2008:28:149-57.

9. Kovacs K, Velich N, Huszar T, Szabo G, Semjen G, Reiczigel J, Suba Z. Comparative study of beta-tricalcium phosphate mixed with platelet-rich plasma versus beta-tricalcium phosphate, a bone substitute material in dentistry. Acta Vet Hung. 2003;51:475-84.

10. Civinini R, De Biase P, Carulli C, Matassi F, Nistri L, Capanna R, Innocenti M. The use of an injectable calcium sulphate/calcium phosphate bioceramic in the treatment of osteonecrosis of the femoral head. Int Orthop. 2012;36:1583-8.

11. Guarino J, Tennyson S, McCain G, Bond L, Shea K, King H. Rapid prototyping technology for surgeries of the pediatric spine and pelvis: benefits analysis. J Pediatr Orthop. 2007;27:955-60.

12. Hu Y, Yuan ZS, Kepler CK, Albert TJ, Yuan JB, Dong WX, Sun XY, Wang CT. Deviation analysis of C1-C2 transarticular screw placement assisted by a novel rapid prototyping drill template: a cadaveric study. J Spinal Disord Tech. 2014;27:E181-6.

13. He D, Zhuang C, Xu S, Ke X, Yang X, Zhang L, Yang G, Chen X, Mou X, Liu A. $3 \mathrm{D}$ printing of $\mathrm{Mg}$-substituted wollastonite reinforcing diopside porous bioceramics with enhanced mechanical and biological performances. Bioactive Mater. 2016;1:85-92. 
14. Faul F, Erdfelder E, Buchner A, Lang AG. Statistical power analyses using G*Power 3.1: tests for correlation and regression analyses. Behav Res Methods. 2009;41:1149-60.

15. Goiato MC, Santos MR, Pesqueira AA, Moreno A, dos Santos DM, Haddad MF. Prototyping for surgical and prosthetic treatment. J Craniofac Surg. 2011;22:914-7.

16. Harris J, Rimell J. Can rapid prototyping ever become a routine feature in general dental practice? Dent Update. 2002;29:482-6.

17. Brown GA, Firoozbakhsh K, DeCoster TA, Reyna JR Jr, Moneim M. Rapid prototyping: the future of trauma surgery? J Bone Joint Surg Am. 2003;85A(Suppl 4):49-55.

18. Kawaguchi Y, Nakano M, Yasuda T, Seki S, Hori T, Kimura T. Development of a new technique for pedicle screw and Magerl screw insertion using a 3dimensional image guide. Spine (Phila Pa 1976). 2012;37:1983-8.

19. Blakeney WG, Day R, Cusick L, Smith RL. Custom osteotomy guides for resection of a pelvic chondrosarcoma. Acta Orthop. 2014;85:438-41.

20. Lu S, Xu YQ, Zhang YZ, Xie L, Guo H, Li DP. A novel computer-assisted drill guide template for placement of C2 laminar screws. Eur Spine J. 2009;18:1379-85.

21. Hu Y, Yuan ZS, Kepler CK, Albert TJ, Xie H, Yuan JB, Dong WX, Wang CT. Deviation analysis of atlantoaxial pedicle screws assisted by a drill template. Orthopedics. 2014:37:e420-7.

Ready to submit your research? Choose BMC and benefit from:

- fast, convenient online submission

- thorough peer review by experienced researchers in your field

- rapid publication on acceptance

- support for research data, including large and complex data types

- gold Open Access which fosters wider collaboration and increased citations

- maximum visibility for your research: over $100 \mathrm{M}$ website views per year

At BMC, research is always in progress.

Learn more biomedcentral.com/submissions 